\title{
Good Public Policy Making: How Australia Fares
}

\section{Richard Curtain}

1 Gore (1999), called the 'prince of policy wonks', has claimed that
'Industrial Age bureaucracies ... have grown far beyond the professional
classes they were envisioned to be, and at times seem to specialise in
immobility and apathy, lacking the leadership and also the freedom to change with
the changing times'. He argues that public policy is about showing leadership and
responding to changed circumstances. He also infers that public policy is about
setting broad directions. How does Australia rate in terms of public policy
leadership and ability to set new policy directions?
The purpose of this paper is to identify the key elements of good public
policy and to assess how well Australia's record stands against the identified
criteria. This exercise is not intended as detached analysis. It is a product of the
author's own 'reflective practice' as an independent public policy consultant over
eight years. In particular, it draws on his involvement in three recent public policy
exercises: the review of post compulsory education and training pathways in
Victoria, the development of policy options to address the barriers to training for
older persons and a paper for the Dusseldorp Skills Forum comparing the
operation of mutual obligation arrangements in Australia and the UK (Curtain,
1999).

The paper uses, as its reference point, recent official statements on new policy directions in the UK, Canada and New Zealand and highlights the reasons for the new directions. It presents an outline of what is good public policy, based on governmental reappraisals in these three countries. Finally, it applies these criteria to assess three recent initiatives by the Commonwealth Government to develop new policy. These initiatives are: the Youth Pathways Action Plan Taskforce, the employment aspects of the National Strategy for an Ageing Australia and the Reference Group on Welfare Reform (the McClure report). Particular attention is given to assessing the latter review as an exercise in good public policy making.

This analysis indicates that there are clear signs that public policy making in Australia, compared with the countries cited above, is still deficient in a number of respects. Methods for identifying and analysing citizens' needs are underdeveloped. This is reflected in the fact that the consultation processes involving the end users of the policies being formulated are often limited or

Richard Curtain is a Melbourne-based consultant specialising in public policy research and analysis related to labour market and vocational education and training issues.His e-mail address is: curtain@netspace.net.au. 
absent. Ways of offering citizens more scope to take the initiative in their dealings with publicly funded services are not canvassed.

The paper concludes with some suggestions on ways to improve Australia's performance in policy design and implementation. It is suggested that more independent sources of policy advice need to be fostered with greater contestability in access to public funding to facilitate this. Another way of improving public formulation is for governments to find more varied ways of seeking input from a wider range of stakeholders, including a large cross section of ordinary citizens. Two ways to improve the environment for policy innovation in Australia are discussed.

\section{Narrow Focus of Public Sector Reforms}

It is now acknowledged that public sector reforms undertaken over the last decade around the world have been too narrow in their focus (Kettl, 2000). There is an emerging consensus in the UK, Canada, US and New Zealand that the reforms have been mostly about internal restructuring to the detriment of good public policy making. The widespread use of the new structural arrangements based on the 'purchaser/provider split' to achieve greater accountability for outcomes has often meant that other aspects of public policy have suffered.

The March 1999 White Paper from the British Labour Government entitled Modernising Government makes this criticism forcefully. The White Paper notes that the management reforms of the last two decades have brought improved productivity, better value for money and, in many cases, better quality services. However, according to the White Paper (UK Government, 1999:11) these reforms have been achieved at the expense of broader issues that should be of concern to government:

... little attention was paid to the policy process and the way it affects government's ability to meet the needs of the people... in general too little effort has gone into making sure that policies are devised and delivered in a consistent and effective way across institutional boundaries - for example between different government departments, and between central and local government. Issues like crime and social exclusion cannot be tackled on a departmental basis. An increasing separation between policy and delivery has acted as a barrier to involving in policy making those people who are responsible for delivering results in the front line.

The Canadians also have identified a decline in policy research capacity in their country (Policy Research Initiative, 1999):

...policy issues and their interactions have become more complex. There is more overlap between issues and across jurisdictions, thus putting a premium on information sharing and on working across traditional policy boundaries. Ever growing volumes of information, easier access 
through technology and greater ranges of information introduced by more horizontal perspectives are challenging everyone's capacity to keep up-to-date.

A Policy Research Initiative was created in July 1996 by the Canadian federal bureaucracy to strengthen the policy capacity of government to deal with more complex policy issues. An important second objective has been to foster wider participation from think tanks and academic institutions in the policy making process (Deputy Minister Taskforces, 1996). The Policy Research Initiative has been particularly successful in achieving the latter objective. Its second national conference held in 1999 attracted 750 participants from a cross section of Canadian society at \$C600 per head. The Policy Research Initiative distributes over 7,000 newsletters and publishes a refereed journal. By 1999, its simple, lowcost web site had registered over 2 million 'hits' from 17 countries (Curtain, 2000a).

The problem of the narrow focus of policy is recognised in New Zealand as well. The State Services Commission of New Zealand has published several studies identifying ways to improve departmental capability to contribute to strategic priorities setting (State Services Commission, 1999). Its recent report Essential Ingredients: Improving the Quality of Policy Advice (State Services Commission, 1999:8 and 14) highlights the 'prevailing short-term focus in policy development' as follows:

the strongest impulses in the public management system are towards action: policy makers react to major problems, formulate quick solutions to them, take decisions, implement these and then move on to the next set of problems. Policy development processes tend, therefore, not to easily accommodate inputs that are reflective or require long lead-times, such as longer-term research and evaluation.

The particular gaps in the New Zealand policy process identified ... are in areas of outcomes evaluation, issues identification (including anticipation of emerging problems), the notion of long-term and forward-looking research-based policy analysis, public consultation, and strategic analysis and management.

\section{Criteria for Good Public Policy making}

Public policy making is first and foremost about determining objectives or societal goals (Encyclopaedia Britannica, 2000). These societal goals refer to 'big ticket' issues such as the principles to underpin the conduct of foreign affairs, how to promote internal social cohesion, to how best to meet citizens' needs during major life cycle changes.

It follows that public policy has to be effective (achieve its goals) and efficient (do so in a way that achieves the greatest possible benefit at the least possible cost). Goal setting in public policy needs to be long-term in perspective. 
This means starting with a comprehensive understanding of the current environment and defining what society's needs are in a way that an appropriate policy response can address. It could, for example, involve developing likely 'futures' scenarios in which a proposed policy might need to operate.

Good public policy also involves attention to process. This includes giving the end users ample opportunity to participate in a variety of ways. It also involves ensuring, for example, that the 'silo' effect of departments operating independently of each other is minimised. The opposite of good policy making is an ad hoc or short-term policy response to an immediate problem. Poor policy making often results from unintended consequences that a piecemeal approach has not taken into account.

In response to the declaration that 'this Government expects more of policy makers', the UK White Paper Modernising Government proposed a set of key principles for the development of a new and more creative approach to policy making (UK Cabinet Office, 1999). An important starting point is to ensure that the policy has a strategic focus in terms of becoming more forward- and outwardlooking. According to the White Paper (p. 9), such a focus requires policy makers to:

- look beyond current activities and programs;

- improve and extend the capacity for contingency planning, and

- learn lessons from other countries by integrating an international dimension into policy making process.

Good policy also needs to be outcome-focused by identifying carefully how the policy will deliver desired changes in the real world. Policy makers also need to ensure that they are inclusive by putting in place policies that take full account of the needs and experience of all those likely to be affected by them, whether they be individuals or groups, families, businesses or community organisations.

Good policy also requires involving those outside government in policy making. This includes consulting with those who are the target of the policy, outside experts, and those who are to implement the policy. Policy decisions also need to be based on a careful appraisal of the benefits any measure seeks to achieve, the costs it entails and the cumulative burden of regulation on those responsible for implementing the policy. Linked to this is also the need for policy makers to improve the way risk is assessed managed and communicated to the wider community.

Finally, good public policy is based on learning from experience. Policy making needs to be a continuous, learning process, not as a series of one-off, isolated initiatives. This requires making use of evidence and research about the problems being addressed. It may also involve making more use of pilot schemes to encourage innovation and to test whether proposed options work. It also requires clearly specifying and evaluating independently the objectives of all policies and programmes and making public the lessons of success and failure and acting upon them. Policy evaluation should also involve obtaining feedback from 
those who implement and deliver policies and services (UK Government, 1999:12).

The following sections of the paper look critically at how well the above principles of good policy making have been applied in three inquiries by the Commonwealth Government. The paper concludes with a discussion of the reasons underlying Australia's approach to public policy and how that approach might be improved.

\section{The Youth Pathways Action Plan Taskforce}

The Commonwealth Government's Youth Pathways Action Plan Taskforce (appointed in September 1999, final report submitted in November 2000) displayed several features that adhere to the above principles of good policy.

\section{Strengths}

The Taskforce was interested in approaches that looked at the needs of individual young people in a more integrated manner. The terms of references were broad in their coverage of a major life episode: the transition to 'independence'. ${ }^{1}$ Its considerations also extended to all those affected by the failure of young people to make a successful transition from education to work, such as family and the community. The comprehensiveness of the Taskforce's approach is shown by its focus on seven aspects of young people's lives, from health to the availability of appropriate services.

The principle of seeking to join up policy across organisational boundaries is also explicitly addressed by aiming to develop and implement a whole-ofgovernment approach. The principle of involving others outside of the responsible government departments was also observed. Captain David Eldridge of the Salvation Army chaired the Taskforce. Other members were drawn from community organisations, academia, and business. More importantly, the Taskforce included two young people representing end users. It was also the stated intention of the Taskforce to identify the kinds of partnerships with other groups in the community with the potential to help young people.

\section{Shortcomings}

However, the deficiencies of the Taskforce as an example of good public policy were several. The absence of an initial consultation or discussion paper to raise issues and possible solutions was a major flaw in how the Taskforce conducted its business. The purpose of such a document could have been to define what constituted a successful transition to 'independence' for young people. Is it achieving full-time work, or a threshold qualification? (see Curtain, 2000b). Or is it something broader and, if so, can it be easily measured? In the absence of a

1 For details of the Terms of Reference see http://youthpathways.detya.gov.au/terms.htm 
definition of independence, it is impossible to know what the Taskforce considered to be a successful outcome in young people's transition to adulthood.

Another deficiency was the lack of mention in the terms of reference of any assessment of the risks or costs to Australian society of having young people failing to make a successful transition to 'independence' (see Natsem (1999) for an estimation of the costs to society of young people leaving school before the final year in Australia). Nor was there mention of what individuals, their families, governments and other stakeholders can do to manage this risk and how best to communicate the consequences of failure to those most exposed.

A basic strategic issue that needed to be addressed in a consultation document was a statement about how the Taskforce views young people. Three approaches are possible: young people perceived as either passive clients of government services who are passing through a series of developmental stages, as autonomous agents able to shape their own destinies or as constrained decision makers. Each starting point offers a fundamentally different approach to the type of policy options that could be developed (White and Wyn, 1998).

The strategic challenge facing the Taskforce was to work out how young people can be, not only at the centre of the refocused policy, but also how they themselves can play a much more active role in policy formulation and program delivery. This may also hold the key to achieving better coordination between departments and agencies, federal and state. Placing more discretionary power in the hands of the end user of the services helps to create a system of rewards for good service delivery, which is now absent in most cases.

However, despite its long gestation, the Taskforce did not produce an interim report. In the absence of a canvassing of innovative options, it could only offer its final report in a 'take it or leave it' fashion. Without adequately preparing the ground for its more innovative options, it is highly likely that State authorities will reject the report's findings or simply fail to respond to the call for more 'joined up' services.

\section{National Strategy for an Ageing Australia}

The purpose of the National Strategy on Ageing is to develop 'a broad ranging framework to identify challenges and possible responses for government, business, the community and individuals to meet the needs of Australians as they age' (Bishop, 1999:7). The National Strategy also aims to take 'a whole of government' approach and will build on work already undertaken to look at possible impacts of ageing in particular areas. The Strategy is focusing on short, medium and long-term policy responses to population ageing as part of a coordinated national framework. Inter-Departmental Committees, drawn from 18 Departments and Agencies, are involved. The four themes are: independence and self-provision; world-class care; healthy ageing; and attitude, lifestyle and community support.

The focus here is on one aspect of the strategy familiar to the author: older people and employment (Cully et al, 2000). Under the theme of independence and 
self-provision, an Issues Paper entitled Employment for Mature Age Workers has been released. The paper's objective is to raise for discussion the longer-term implications of Australia's ageing workforce for the social and economic opportunity of the nation. However, after presenting data on demographics, the changing nature of work, and the attitudes of employers, employees, the community and current initiatives, the paper concluded with just one paragraph on 'future directions' (Bishop, 1999b:44).

...Mature age workers need to take responsibility for their ongoing training and skilling. The ability to be adaptable and flexible in the mature age employment market is a key element for success. It is important to ensure that the Commonwealth Government, in collaboration with the business sector, is able to promote a climate where mature age workers are not encouraged out of the workforce simply as a result of their age. The challenge is to foster a cultural change in the way that the community values mature age workers and encourages initiatives which support their longer participation in the workforce.

The Issues Paper, despite its whole-of-government approach, failed to foreshadow any initiative whatsoever. No reference was made to an extensive literature on policy initiatives on the employment of older persons being implemented by governments and enterprises in Europe and North America. Ways of involving older citizens as active participants in the policy formulation process were not suggested. Nor was there any indication of how Government might initiate or facilitate the cultural change suggested among the other stakeholders such as employers, community groups and individuals. The above conclusion to the paper suggests that policy coordination through seeking consensus among a range of agencies and departments has led, in this case, to a non-outcome.

\section{Reference Group on Welfare Reform}

The focus of the Commonwealth Government's review of the welfare system has been on ways to prevent and reduce welfare dependency. This was defined as encouraging those receiving social security income support to move from being passive recipients to being active participants in the labour market or socially active as volunteers. The review began in November 1999, issued an interim report at the end of March 2000, and a final report on 16 August 2000. The Commonwealth Government issued its response to the Review on 14 December 2000 .

\section{Strengths}

How the Reference Group on Welfare Reform was set up and conducted its inquiry demonstrates a number of features that exemplify good practice. The membership of the Reference Group included service providers, academics, and 
social policy specialists, although, as noted below, significant stakeholders such as the end users of the social security system were missing. An extensive consultation process before and after the publication of an interim report gave many stakeholders a chance to contribute to its deliberations. The consultation process generated 360 formal submissions prior to the release of the interim report. This was followed by distributing feedback questionnaires to all those who made submissions and focus group discussions with key stakeholders members. Some income support recipients also participated through focus group discussions. Other good policy features exemplified are a survey of international developments relevant to the review, a critical appraisal of the shortcomings of existing arrangements and the specification of key outcomes to be achieved.

\section{Shortcomings}

However, against the benchmark of good policy criteria identified above, the final report of the Reference Group has three major shortcomings. The first is that the key outcomes are specified in an open-ended way without specific targets. Two outcomes are specified in terms of achieving 'a significant reduction' (in the incidence of jobless families and jobless households and in the proportion of the working age population that needs to rely heavily on income support) without specifying what constitutes 'a significant reduction'. A third specified outcome, as stated, is not measurable ('Stronger communities that generate more opportunities for social and economic participation').

The second shortcoming of the report is its narrow departmental focus. Despite the identification of major problems in coordinated service delivery, the department responsible for funding and regulating mainstream employment services was not represented on the Reference Group. The Welfare Review's Interim report (Reference Group on Welfare Reform, 2000a:9) noted that:

from the individual's perspective, the linkages between services are not always clear and there can be gaps in assistance, as well as conflicting priorities ... Difficulty can be experienced in obtaining more appropriate assistance, as an individual's needs change.

The Review's final report (Reference Group on Welfare Reform, 2000b:14) also noted that the current structure of mainstream (for example, Job Network) and specialist employment services (for example, Specialist Disability Employment Services) results in people being unable to move between these services according to need. Also noted was the inadequate servicing of people who are not catered for by either market. The final report concluded that that the current structure of service provision needs to be examined and options developed that ensure barriers are broken down so people can move more easily between programs as their circumstances change.

However, the other federal departments with responsibility for a range of programs aimed at assisting people into work, including the Job Network, namely the Department of Employment, Workplace Relations and Small Business and the 
Department of Education, Training and Youth Affairs, were not represented on the Reference Group. Nor were they even mentioned as key stakeholders in the final report's recommendations. The report's recommendations overwhelmingly refer to the agencies (such as Centrelink) and the programs that are the responsibility of the Department of Family and Community Affairs portfolio. Only two out of 56 recommendations relate (albeit somewhat indirectly) to the operation of the Job Network.

From the perspective of good public policy, the third major shortcoming of the work of the Welfare Review is the uncritical emphasis it places on 'individualised service delivery' as a major recommendation. 'Individualised service delivery' refers to the use of case managers and other brokers to assess and stream individuals into 'levels of service intervention based on their capacity for economic and social participation' (Reference Group on Welfare Reform, 2000a).

From the perspective good policy making, two flaws can be identified in this recommendation and supporting analysis. The first is the failure to provide an assessment of the costs involved against the costs or risk assessment of not implementing this approach. Mead notes that 'supervisory paternalism' makes severe demands on the capacities of government and is difficult to implement well (Mead, 1997). Feedback from the Review's own consultations also noted that, to work well, individualised service delivery would require an huge investment in resources in the form of sufficient staff resources that need to be fully trained to carry out the complex assessments (Reference Group on Welfare Reform, 2000b:15). There was no attempt in the final report to specify or cost out what these resources might involve.

The second flaw in 'individualised service delivery' from a good policy perspective is the wide scope for discretionary power it gives to case managers. One obvious risk of this approach to service delivery is the reinforcement of the dependent attitudes of the income support recipient. Although the interim report notes the importance of individuals making their own choices, the Review's two reports do not suggest any ways that this can be fostered in the face of the powers recommended for case managers.

The need for an alternative approach that improves the power balance between the individual reliant on social security support and his or her case manager was brought home to the author last year when conducting focus groups with long-term unemployed, older persons (aged 45 and over). Their accounts of dealings with case managers under Job Network's Intensive Assistance Program for the long term unemployed suggested that case managers are exposed to a major moral hazard. Although funded to provide a range of forms of assistance, the Job Network operator has a strong incentive, because of open-ended nature of the assistance available, to provide their 'client' with as little information as possible about their options so as to maximise profits. This can mean that, in one instance cited by a focus group participant, a short computer training course (six weeks) was approved by the Intensive Assistance case manager rather than the more extended TAFE course sought by the long term unemployed person. This latter option, the unemployed 45 year old man saw as a more effective way in the 
long-run of improving his employment security. Other instances concerning the limited training options available from their case manager were cited by other older long-term unemployed.

One suggestion to overcome this problem would be a Government requirement that a customers' or citizens' charter be provided for those participating in any form of individualised service delivery funded by government. At present, the service charters of many federal government departments and agencies do not extend to publicly funded services delivered by non-government service providers. This charter could spell out what options and resources are available to allow 'clients' to negotiate with their case managers on a more equal footing. The purpose of such a charter would be to help long-term unemployed persons to learn from the experience of making their own choices through a negotiated process.

Another way to give 'clients' of the system more awareness of their entitlements would be to explore ways for a direct flow of funds to end users of the service. Individuals in dealing with Centrelink case officer or a case manager would need to be provided with sufficient information to make the best choice. However, this is likely to be a very different relationship to one based solely on a case officer's own assessment of what is appropriate. The lack of attention in the Review's reports to the perspective of income support recipients is shown by their absence on the Reference Group and a lack of awareness of the limitations of individualised service delivery as a vehicle for reducing welfare dependency. It is difficult to avoid the conclusion that a service provider perspective underpins many of the Review's major recommendations.

\section{Factors Inhibiting Policy Innovation}

What is immediately noticeable about the state of debate about public policy making in Australia is the absence of equivalent official statements about what constitutes good policy similar to those of the British, Canadian and New Zealand Governments. The capacity to reflect critically on the shortcomings of existing policy processes and to draw lessons on how to improve them in toto does not appear to be a feature of the operating environment of Australian Governments or the Australian Public Service. The Commonwealth Government-initiated inquiries, discussed above, have in some aspects sought to address the shortcomings of past approaches to policy making. However, in the absence of a blue print of what constitutes good policy, each of these attempts has major gaps in the range of issues addressed, the stakeholders involved and deficiencies in the assessment of the risks involved.

It is beyond the scope of this paper to identify and expound on the range of factors that might explain the constraints affecting the public policy setting process in Australia. These factors include the short term focus produced by the electoral cycle, arbitrary timing of elections and the legacy of our federal system where the Commonwealth Government does not have prime responsibility constitutionally for addressing the needs of citizens in crucial areas such as 
education and health. It can be argued that there is also a defensiveness among Canberra bureaucrats about Ministers having access to other sources of policy advice. However, let me highlight two deficiencies of the policy formulation process without further elaboration as a means of suggesting new approaches. One is the lack of innovative ways of consulting ordinary citizens about what issues public policy should address. The other is the lack of alternative sources of policy advice in Australia compared with the USA, UK and Canada.

\section{Some Suggestions for Change}

\section{Consulting ordinary citizens}

Innovative forms of consultation now used in the UK and North America could better inform the policy process. These include surveying randomly selected members of the public through a mechanisms known in the UK as People's Panels, based on a random sample of 5,000, to seek feedback on policy ideas and to assess the effectiveness of program implementation. Other innovative forms of consultation are 'deliberative polling' and 'deliberative dialogue'. The former is a means of involving the public through scientific random sampling in intensive small group discussions to work through complex public policy issues. It is a technique that has been used to explore 'big issue' policy change such as the republic debate in Australia and devolution in Scotland.

Deliberative dialogue is a structured, face-to-face method of public interaction that takes place within small groups at community level over an extended time. This method has been used to canvass the issues to do with parents' choice of schools in the United States. The benefit of both methods is that they provide a means for others in the community interested in policy change to better inform members of the public to understand the complexities of an public policy issue so that they can more easily come to an informed opinion about the issue.

\section{Fostering alternative sources of policy advice}

Governments in Australia tend to view the bureaucracy as the primary, if not the sole, source of public policy advice. In the words of the Minister Assisting the Prime Minister for the Public Service '... as an ongoing Service, it provides an unparalleled source of knowledge and experience ... to the government of the day' (Kemp, 1999). However, because public policy makers in the Public Service work within a hierarchical organisation structure, the market for new policy ideas can be viewed as a monopsony (Hamel, 1999). It requires only a single rejection from one person at the top of the hierarchy for the fate of the policy idea to be sealed. Senior managers in hierarchical organisations, whether they are public bureaucracies or operating in the market, have already 'made it' with all that this infers about attitudes to past practice. This means that they are likely to be the 
most conservative about new ideas because they have the most emotional capital tied up in defending past policy actions (Hamel, 1999; see also Curtain, 2000c).

The challenge for those who believe that public policy is not simply the province of public servants is to generate the conditions that remove the monopsony to create greater contestability for policy ideas. One solution for achieving this would be for independently funded public policy think tanks to conduct their own research and to publicise new ideas. There are several reasons that could be given, not able to be elaborated on here, that make this a difficult option in Australia.

An alternative approach, proposed by Gary Hamel in relation to how established private sector firms can generate new ideas, is for Government to set up a fund to provide 'venture capital' for new policy initiatives (Hamel, 1999). The fund, modelled on a similar arrangement in Royal Dutch/Shell, could be presided over by a group of more open-minded senior public servants (likely to be those with alternative career options outside the public service) to allocate money to path breaking ideas submitted by interested parties.

Such a fund could be analogous to a 'policy ideas' version of the Australian Research Council. Interested parties in federal or State Government departments, advocacy groups, universities and others could seek funding, in a contestable way, to not only develop policy options but also to conduct a pilot or series of pilots to test their viability or to fine tune proposals. The Fund could also help to underwrite national and regional conferences on particular policy issues and support other initiatives to promote contact with all those interested in public policy as societal goal setting.

Australia needs mechanisms to not only generate new policy ideas that are a departure from the past. We also need ways to ensure that the new ideas can be further tested and implemented on a large scale where they are judged to be viable.

\section{References}

Bishop, B., The Hon MP Minister For Aged Care (1999a), The National Strategy For An Ageing Australia, Background Paper, Ausinfo, Canberra,

Bishop, B., The Hon MP Minister For Aged Care (1999b), Employment for Mature Age Workers Issues Paper, The National Strategy for an Ageing Australia, Ausinfo, Canberra.

Cully, M., R. Curtain, A. VandenHeuvel and M. Wooden (2000), 'Participation in, and Barriers to Training: the Experience of Older Adults', Australasian Journal on Ageing 19(4):172-179.

Curtain, R. (1999), Mutual Obligation: Policy and Practice in Australia Compared with the UK, Dusseldorp Skills Forum, Sydney, http://www.dsf.org.au.

Curtain, R. (2000a), 'A Fresh Approach to Policy Research: Canada's Policy Research Initiative', Canberra Bulletin of Public Administration 98: 54-56. 
Curtain, R. (2000b), How Young People are Faring in 2000: An Update About the Learning and Work Situation of Young Australians, Dusseldorp Skills Forum, Sydney, http://www.dsf.org.au.

Curtain, R. (2000c), 'Towards greater transparency in policy-making', Canberra Bulletin of Public Administration 96:1-5.

Deputy Minister Taskforces, (1996), Managing Horizontal Policy Issues, Government of Canada, Ottawa, http://policyresearch.schoolnet.ca/keydocs/index-e.htm.

Encyclopaedia Britannica (2000), 'Government Economic Policy, Public Goods'.

Gore, A. (1999), Remarks as prepared for delivery by Vice President Al Gore to the opening session of the international conference Transforming Governments in the 21st Century, Washington DC, January 14-15, http://www.21stcentury.gov/conf/.

Hamel, G. (1999), 'Bringing Silicon Valley Inside', Harvard Business Review, Sept-Oct.

Kemp, D., The Hon MP, Minister Assisting the Prime Minister for the Public Service (1999) 'A New Act for a New Century', Canberra, 2 December (Speech), http://www.psmpc.gov.au/media/ministerspeech2dec.htm.

Kettl, D. (2000), The Global Public Management Revolution: a Report on the Transformation of Governance, Brookings Institution Press, Washington DC.

Mead, L. (1997), The New Paternalism: Supervisory Approaches to Poverty, Brookings Institution, Washington DC.

Natsem (1999), The Cost to Australia of Early School-Leaving, University of Canberra (Report Commissioned by Dusseldorp Skills Forum, Sydney, http://www.dsf.org.au.

Policy Research Initiative (Government of Canada) (1998), 'Outlook: The Policy Research Initiative's Business Plan', Ottawa,

http://policyresearch.schoolnet.ca/keydocs/perspectives/perspectives-e.htm.

Policy Research Initiative (Government of Canada) (1999), 'Policy Research in Canada: A Capacity for the Future', Ottawa, March (A Discussion Document), http://policyresearch.schoolnet.ca/keydocs/cap/.

Reference Group on Welfare Reform (2000a), Participation Support for a More Equitable Society, Interim Report, Ausinfo, Canberra, http://www.facs.gov.au.

Reference Group on Welfare Reform (McClure Chairman) (2000b), Participation Support for a More Equitable Society, Ausinfo, Canberra (Final Report), http://www.facs.gov.au.

State Services Commission (NZ) (1999), 'Essential Ingredients: Improving the Quality of Policy Advice,' Auckland, (Occasional Paper No. 9).

UK Government (1999), Modernising Government, White Paper presented to Parliament by the Prime Minister and the Minister for the Cabinet Office by Command of Her Majesty, London, March. 
White, R. and J. Wyn (1998), 'Youth Agency and Social Context', Australian and New Zealand Journal of Sociology 34(3):23-38.

Youth Pathways Action Plan Taskforce (1999), Pathways Post Newsletter Issue 1 (November).

This paper is a substantially revised version of an initial presentation to the Institute of Applied Economic and Social Research, University of Melbourne on 8 May 2000 and subsequently to the Centre for Public Policy, University of Melbourne, 25 July 2000. The author would like to thank seminar participants for their comments as well as Hugh Davies for his feedback and support. The author would also like to acknowledge the helpful comments of the Journal's editor and two anonymous referees. 